\title{
'The Polluter Pays': Backward-Looking Principles of Intergenerational Justice and the Environment
}

\author{
Daniel Butt \\ Forthcoming in Jean-Christophe Merle (ed.), Spheres of Global Justice (Dortrecht: Springer)
}

Pollution frequently imposes costs upon human communities. This happens both when time and resources must be expended in order to reverse the effects of polluting acts, and when the pollution itself affects the abilities of the communities in question to live their lives. Sometimes the community which suffers in this way is the community which has caused the pollution, but at other times one community suffers as a result of another's actions. In a world divided into sovereign states, with extremely limited mechanisms of international redistribution, this can lead to some countries bearing the costs of others' polluting actions. Is this right? How should we allocate the costs associated with pollution?

The purpose of this paper is to provide a limited degree of theoretical support for two historical principles for the allocation of remedial responsibility for paying these costs. These remedial principles are based upon particular forms of backward-looking connection with the pollution in question. The suggestion is that we can have reasons to pay the costs of pollution when we are members of communities which were responsible for the original polluting acts in question and/or which have benefited from the polluting acts. Often, in practice, these two forms of morally relevant connection will coincide, so that the community which was responsible for the pollution is the community which has benefited from it - but there is no necessary connection between the two, and it is my contention that either can give rise to remedial obligations. In seeking to provide support for backward-looking remedial duties in some cases, my aim is to bolster understandings of the principle of Common but Differentiated Responsibility (CBDR) which place the primary burden of meeting the costs of pollution upon those communities which caused the pollution in the first place. Thus, in supporting the "beneficiary pays" principle in general, and the "polluter pays" principle in some cases, I challenge interpretations of CBDR which maintain that backward-looking principles are unfair, since they impose duties upon present day generations who were not themselves responsible for the polluting acts in question. ${ }^{1}$

This paper has four sections. The first differentiates between benefit-based and responsibilitybased accounts of remedial obligations. The second defends both these backward-looking accounts from a commonly voiced objection based on the "non-identity problem". The third outlines a version of the responsibility-based account which accords remedial duties in connection with historic pollution to present day generations, based on their communities' ongoing failure to rectify the effects of the original unjust polluting acts. The fourth examines the relevance of this model to the particular issue of the costs of climate change stemming from the emission of greenhouses gases (GHGs).

\section{Benefit-based and responsibility-based accounts}

\footnotetext{
${ }^{1}$ An example of such an approach is that of Simon Caney - see Caney, "Cosmopolitan justice, responsibility and global climate change”, Leiden Journal of International Law 18 (2005), 747-775. at pp. $771-2$.
} 
The claim that the costs associated with various forms of pollution should be met, in full or in part, by the national communities which were responsible for the polluting acts in question is commonly made in real world policy debates. It is generally known as the "polluter pays" principle, despite the evident fact that it suggests in relation to historic pollution that the costs should be paid by the descendants of the polluters, rather than by the polluters themselves. The claim has been made most prominently within the context of the costs associated with climate change, which are thought to be the result of the emission of GHGs, dating back to the major increase in such emissions caused by the Industrial Revolution. It represents an important element - though only an element - of the principle of Common but Differentiated Responsibility explicitly formulated in Principle 7 of the Rio Declaration, which states:

In view of the different contributions to global environmental degradation, States have common but differentiated responsibilities. The developed countries acknowledge the responsibility that they bear in the international pursuit of sustainable development in view of the pressures their societies place on the global environment and of the technologies and financial resources they command. ${ }^{2}$

The CBDR accepts that all peoples of the world share a common heritage, but calls upon the industrialized developed states to take the lead in addressing the problems of climate change. As Paul Harris writes, "[the] principle is grounded in shared notions of fairness: the developed countries are disproportionately responsible for historical GHG emissions and have the greatest capacity to act." ${ }^{33}$ CBDR thus runs together two ideas: those of capacity and culpability. Capacity relates to the differential ability of modern day states to pay for the costs of climate change. Culpability looks to the historical record to ask which states have been, and continue to be, causally responsible for the emissions which lead to climate change. Thus Vito de Lucia writes that, "The CBDR can be said, in synthesis, to express the need to evaluate responsibility for the remediation or mitigation of environmental degradation based on both historical contribution to a given environmental problem and present capabilities: it is a guiding principle of international cooperation and solidarity.",

Why do we need the capability element here? Why not simply ask whose fault the emissions are? If someone smashes one of the windows of my house, I do not ask who in the village is best placed to pay for its repair. I rather insist that the person responsible for breaking it bears the cost. Insofar as the costs of pollution are the fault of particular agents, it seems as if we are dealing with a question of rectificatory justice - which is, by its nature, backward-looking. Why include the forward-looking capacity element? One significant objection to the culpability approach stems from the claim that past generations, not current day moral agents, were responsible for a large part of the problematic emissions. Is it not unfair to hold present day generations responsible for the actions of their ancestors $?^{5}$ It may be true that we have particular kinds of links to our own ancestors which we do not have to past generations who lived elsewhere in the world, but it is certainly controversial to maintain that our connection is sufficient for us to share, or inherit in some way, responsibility for their actions. This is particularly problematic from the

\footnotetext{
${ }^{2}$ The Rio Declaration on Environment and Development, United Nations Conference on Environment and Development, June 13, 1992.

${ }^{3}$ Paul G. Harris, "Common but differentiated responsibility: The Kyoto Protocol and United States Policy", Environmental Law Journal 7 (1999), 27-48 at p. 28.

${ }^{4}$ Vito De Lucia, "Common but differentiated responsibility", in Cutler J. Cleveland (ed.), Encyclopedia of Earth, (Washington, D.C.: Environmental Information Coalition, National Council for Science and the Environment, 2007). [Retrieved September 6, 2007]. <http://www.oeearth.org/article/Common_but_differentiated_responsibility>

${ }^{5}$ For an argument which uses this claim to shift the attribution of costs away from culpability onto capacity, see Darrel Moellendorf, Cosmopolitan Justice (Boulder, Colorado: Westview, 2002), pp. 99-100.
} 
liberal individualist perspective which dominates much of contemporary Western political thought. If one envisages one's relationship with the past from a different, more communitarian perspective, the thought is perhaps less troubling. For example, many writers have traditionally conceived of the nation as an entity which stretches across different generations. This idea is seen clearly in Edmund Burke's description of the nature of national membership:

It is a partnership in all science; a partnership in all art; a partnership in every virtue, and in all perfection. As the ends of such a partnership cannot be obtained in many generations, it becomes a partnership between those who are living, those who are dead, and those who are to be born. ${ }^{6}$

Those modern day writers who subscribe to axiological individualism have struggled to make sense of such arguments. In contrast to communitarian thinkers who accept that one's identity as a member of a particular national community can give rise to involuntarily acquired duties, the voluntarism key to so much contemporary political thought generally resists moves which seem to hold the child responsible for the sins of the parent. ${ }^{7}$

Typically, therefore, within the debate over environmental justice in general, and over greenhouse emissions in particular, another tack has been used in order to justify a backward-looking approach to the allocation of remedial responsibilities. This consists of arguing that present day generations have benefited from the polluting actions of their ancestors, and so possess special responsibility for addressing environmental problems as a result of the benefit they have received. This is, for example, largely the approach adopted by Eric Neumayer. Neumayer accepts the force of the claim that current generations should not be held morally responsible for the actions of their ancestors, but draws parallels with the debate over the rectificatory duties stemming from the Second World War possessed in the present day by certain German corporations and Swiss banks. He explicitly links their ongoing compensatory duties to the contingent fact that they are, in the present day, benefiting from historic injustice, so that they are forced by popular opinion to be accountable "whether legally required to do so or not because it is felt that they benefited from the wrongs of the past." ${ }^{\prime 8}$ This, Neumayer suggests, is directly comparable to the case of current day responsibility for remedying the effects of greenhouse emissions:

The fundamental counter-argument against not being held accountable for emissions undertaken by past generations is that the current developed countries readily accept the benefits from past emissions in the form of their high standard of living and should therefore not be exempted from being held accountable for the detrimental side-effects with which their living standards were achieved. ${ }^{9}$

It seems to me that the claim here that those in developed countries "readily accept the benefits from past emissions in the form of their high standard of living" is mistaken, and is not needed for this account to work. It is hard to see how living in a developed country can really be seen to involve a voluntary acceptance of such benefits - this is a claim which the literature on political obligation has called into serious doubt. ${ }^{10}$ What could be said is that the benefits that those in the

\footnotetext{
${ }^{6}$ Edmund Burke, cited in Andrew Reeve, Property (London: Macmillan, 1986), p169.

${ }^{7}$ For an example of such a communitarian approach, see Alastair MacIntyre, After Virtue: A Study in Moral Theory (London: Duckworth, 1987).

${ }^{8}$ Eric Neumayer, "In defence of historical accountability for greenhouse emissions", Ecological Economics 33 (2000), 185-92 at p189.

${ }^{9}$ Neumayer, p189. A similar argument, which again runs together the benefit and responsibility approaches, can be found in Lavanya Rajamani, "The principle of common but differentiated responsibility \& the balance of commitments under the climate regime”, Review of European Community and International Environmental Law 9 (2000), 120-131 at p. 122.

${ }^{10}$ See, for example, the arguments in A. John Simmons, Moral Principles and Political Obligations (Princeton: Princeton University Press, 1979).
} 
developed world receive as a result of their states' historical industrialization are of such obvious advantage to nearly all conceptions of the good that we are justified in treating modern day individuals as if they had voluntarily accepted the benefits in question, since we presume that they would have accepted them if they had, originally, has a choice as to whether to receive them or not. This closely follows the account of "presumptive benefit" which George Klosko has developed in a political obligation context. ${ }^{11}$ But it seems best to suggest that it is the fact of benefit, rather than its acceptance, which is generating present day obligations. This same basic point is made in much greater depth by Axel Gosseries. ${ }^{12}$ Gosseries argues that those who benefit from harm to others may be described as free-riders, and can face obligations to compensate the victims of the harm in question. Thus, one version of his account of morally objectionable freeriding of this kind holds that:

I am a morally objectionable free-rider if I obtain a benefit from an action or scheme without paying all or part of its cost, at least until the point where the costs participation imposes upon me would start to outweight the benefits I derive from it, and in the same proportion as other people incur costs for the benefit they get from the scheme.

So the obligations of present day national communities to pay the costs of actions of their ancestors are, under Gosseries' "no net cost" proviso, to a duty to pay compensation up to the point where they are no longer benefiting, and may be further limited if we accept the proportionality proviso.

I find this argument compelling. ${ }^{13}$ However, it is just one of two plausible backward-looking arguments which link those responsible for pollution with contemporary national communities, and so hold that particular present day parties bear duties to pay the costs associated with dealing with pollution. As well as linking national communities to the past in terms of benefit, we can also describe a sense of ongoing responsibility in relation to pollution, insofar as a failure to fulfill rectificatory duties which one possesses in relation to pollution may be seen as an ongoing injustice. This approach is outlined in Section 3. The key point here is to stress the theoretical separateness of the benefit and the responsibility accounts. In the context of GHG emissions, we would expect the communities which have historically produced the most emissions to have benefited significantly from the industrialization which caused these emissions, though not necessarily to the same degree. But it is also likely that we will find that other communities have benefited from these emissions, and so will possess remedial duties under the "beneficiary pays" principle. Furthermore, as will be argued, there are likely to be other historic acts of pollution which have only caused harm in the present day, meaning that there are no evident beneficiaries. In such cases, if a backward-looking principle is to be employed, it will have to be some variant of the responsibility approach.

\section{2 - The Non-Identity "Problem".}

In a recent article, Simon Caney has challenged the plausibility of the "beneficiary pays" principle. ${ }^{14}$ Noting (rightly) that it is conceptually distinct from the "polluter pays" principle, in

${ }^{11}$ George Klosko, "Presumptive benefit, fairness, and political obligation", Philosophy and Public Affairs 16 (1987), 241-9.

${ }^{12}$ Axel Gosseries, "Historical emissions and free-Riding", Ethical Perspectives 11 (2004).

${ }^{13}$ I lay out an account of how benefiting from injustice can give rise to general rectificatory duties in Daniel Butt, "On benefiting from injustice", Canadian Journal of Philosophy 37 (2007), 129-152, which was written prior to seeing Gosseries' piece.

${ }^{14}$ Caney, "Cosmopolitan justice, responsibility and global climate change". 
that it can result in placing costs upon parties with no connection with the act of polluting other than the fact they happen to benefit from it, he goes on to argue that the individualist account of the beneficiary pays principle" is "more problematic than it may first seem". His reasoning here draws upon Derek Parfit's account of the "non-identity problem". He writes:

Parfit begins with the statement that who is born (which particular person) depends on exactly when their parents mated. If someone's parents had mated at a different time, then, of course, a different person would have been born. It follows from this that the policies that persons adopt at one time will affect who will be born in the future. ${ }^{15}$

Caney imagines a case where we build factories in the present day which have no immediate malign effects, but which release poisonous fumes in 300 years time. This leads to the birth of different people than those who would have been born had the factories not been built. He suggests that it follows for Parfit that those affected by the poisonous fumes in the future cannot say they have been harmed by our factory building policy, since they would not have existed had the policy not been enacted. Caney maintains that a very similar point can be made against the "beneficiary pays" principle. He claims that the principle maintains that policies of industrialization have benefited people who are currently alive, but just as one cannot be harmed by an action which causes one to come into existence, so one cannot have one's standard of living improved by such an action. He writes:

We cannot say to people, "You ought to bear the burdens of climate change because without industrialization you would be much worse off than you currently are." We cannot because without industrialization the "you" to which the previous sentence refers would not exist. Industrialization has not brought advantages to these people that they would otherwise be without. And since it has not we cannot say to them, "You should pay for these because your standard of living is higher than it would have been." For this reason the ["beneficiary pays" principle] is unable to show why members of industrialized countries should pay for the costs of the industrialization that was undertaken by previous generations. ${ }^{16}$

This is a serious challenge to backward-looking principles of rectificatory justice. In disputing the meaningfulness of ideas of "benefit" and "harm" when counterfactuals are used which made reference to non-existent persons, it seems to threaten both the "polluter pays" and the "beneficiary pays" principle. If we cannot meaningfully say that one group has benefited from significant historic acts of pollution, it seems also to follow that we cannot say that another has been harmed (assuming, at least, that we do not think their lives are so bad that it would be better for them had they never existed.) The very idea that historic instances of pollution have harmed some and benefited others in the present day is called into question. Indeed, the non-identity problem is often cited as a reason why present generations do not face duties to rectify historic injustice in general. So Samuel C. Wheeler III , for example, maintains, "I take it as a premise that an individual is entitled to reparations for an unjust event only if the individual would still exist if the unjust event had not happened."

What to make of the non-identity problem in this context? Should we accept the conclusion that actions which make a difference to who it is that comes into being cannot be said to harm or benefit the individual in question? The literature on the subject is full of imaginative examples, whereby individuals are said to owe their existence by an event which has what would otherwise

\footnotetext{
${ }^{15}$ Caney, p. 757. Parfit makes the argument in Reasons and Persons (Oxford: OUP, 1984), 351-80.

${ }^{16}$ Caney, p. $757-8$.

${ }^{17}$ Samuel C. Wheeler III, "Reparations reconstructed", American Philosophical Quarterly 34 (1997), 301318 at p. 302. See also Christopher Morris, "Existential limits to the rectification of past wrongs", American Philosophical Quarterly 21 (1984), 175-82.
} 
be seen as a negative effect on their lives. Caney's pollution example involves those living 300 years from now, but we could equally imagine, for example, two children who have physical defects as a direct result of the effects of the polluting activities of a multinational corporation. One child is conceived just before the pollution in question, the other soon after. If we think that the circumstances of the latter's conception were affected by the act of pollution itself, it appears as if only one of these children has been harmed. There are two related issues at stake here. The first concerns whether it is wrong to perform actions which will leave individuals worse off than the different individuals who would otherwise have been born would have been had the actions not taken place. The second concerns whether individuals affected in such a way are morally entitled to compensation for the effects of the actions, even though it appears that they would not have existed had the actions not been performed. Insofar as we are interested in the idea that present generations can be said to have benefited or to have been harmed by historic pollution, it is the second question which is of primary importance here, although the first has to date received most attention from scholars. How should it be answered?

There are three obvious responses. The first is to accept the apparent logic of the case, and maintain, for example, that one cannot be harmed by actions which caused one to come into being. It must immediately be noted that, for many, this approach appears to have extremely counter-intuitive consequences, such as the suggestion that only one of the children in the example above is morally entitled to be compensated. Whether this lack of fit with what I take to be standard intuitive responses to such cases is a problem rather depends on the methodology which different moral and political theorists employ. Probably the dominant methodological approach amongst contemporary analytical political theorists today is Rawls's technique of seeking to find a "reflective equilibrium" of our considered judgments, stemming from our intuitive beliefs, and the principles of right and wrong we draw from these judgments. ${ }^{18}$ So adopting the first approach would mean ignoring or revising our intuitive convictions about such examples. David Heyd, for example, argues that the method of reflective equilibrium is inappropriate in this context, since most people are "systematically confused" in their beliefs concerning issues such as the identity of future persons. For Heyd, this means that "the dynamics of creating a reflective equilibrium has no firm Archimedean point from which mutual testing and revision can start". ${ }^{19}$ His startling conclusion - which he labels "generocentrism" - is that those living in the present day have no obligations of justice to the vast majority of future individuals. ${ }^{20}$ The second obvious response is to insist that the intuitive response to such examples must be right, and effectively to disregard the non-identity problem altogether. Such a response sees the non-identity problem as a paradox: ${ }^{21}$ of philosophical interest until such a point as it can be properly explained (should such a thing be possible), but not something which should guide actions in the real world, just as the fact that Achilles is unable to resolve Zeno's paradoxes would not give him good reason to refuse to give a tortoise a head start in a running race. ${ }^{22}$ The

\footnotetext{
${ }^{18}$ For discussion, see T. M. Scanlon, "Rawls on Justification", in Samuel Freeman (ed.), The Cambridge. Companion to Rawls (Cambridge: CUP, (2003), 139-167.

${ }^{19}$ David Heyd, Genethics: Moral Issues in the Creation of People (Oxford: University of California Press, 1992), p. 71.

${ }^{20}$ Thomas Schwartz draws a similar conclusion in "Obligations to posterity", in in R. I. Sikora and Brian Barry (eds.), Obligations to Future Generations (Philadelphia: Temple University Press, 1978).

${ }^{21}$ Gregory Kavka notably uses the terminology of "paradox", noting that the argument which rests on the non-identity problem to reach the conclusion that we have no moral obligations to future persons "moves by a correct route from plausible premises about biology, personal identity, and moral obligation to a strongly counterintuitive conclusion." Kavka, "The paradox of future individuals", Philosophy and Public Affairs 11 (1982), 92-112 at p. 95.

${ }^{22}$ See Aristotle's Physics, in Jonathan Barnes (ed.), The Collected Works of Aristotle (Oxford: OUP, 1991), pp. 404-5 .
} 
question of whether we have free will is analogous here. It is not unusual to find political theorists who are unable to give (or unwilling even to try to give) a convincing argument from first principles as to why individuals have free will, but who nonetheless are willing to take the existence of free will as a given within their theoretical accounts and make practical policy prescriptions on this basis. The third obvious response is collectivist in nature. It can accept that particular individuals have not been harmed or have not benefited from historic polluting acts as individuals, but nonetheless maintains that the groups to which they belong can be said to have been been harmed or to have benefited. Thus, for example, Edward Page can accept that "the non-identity problem demonstrates that there will be few, if any, cases where a future person will be rendered worse off by their ancestors' profligate emission of GHGs, because these people would not have existed had these profligate actions not been performed", ${ }^{23}$ but nonetheless maintain that such emissions are wrong, as they fail to treat the communities which future persons will belong to with the concern and respect which they are due in their own right. ${ }^{24}$ Evidently, such a communitarian approach requires a notable departure from conventional understandings of axiological individualism, and so will seem mysterious to many, particularly if it goes beyond the claim that we should show respect and concern for future groups to the further claim that such groups can be owed compensation if they are not treated with said concern and respect. ${ }^{25}$

There is a significant cost attached to each of these approaches. In fact, I do not think we need adopt any of them. To invoke the non-identity problem in the context of either the "polluter pays" or the "beneficiary pays" principle is to misunderstand the nature of the counterfactual reasoning which needs to be adopted when thinking about these kinds of cases. Whenever we make an argument about harm and benefit, we compare two states: the real world, and a different, counterfactual state, which does not exist, but which, we suppose, could have existed. Working out which counterfactual to use can be extremely complicated. The point Caney is making in the above quotation is that such counterfactual reasoning cannot take place in an instance where an act of injustice caused an individual to come into being. If the individual does not exist in one of the states we are considering, no comparison can be made. This makes an assumption, however, as to what is the appropriate counterfactual to employ. Caney uses the example of a factory which releases poisonous fumes in 300 years time. So, let us take an individual, X. Let us suppose that she has some disease as a result of the poisonous fumes, which reduces her welfare from 10 units to 7 units. Note the counterfactual here - we are comparing her real world health - at level 7 with a belief about what her normal level of functioning would be in a situation where the fumes have not damaged her health. The claim of Caney is that this counterfactual is not available, since if there are no fumes, there is no $\mathrm{X}$. But is this necessarily so?

Consider again Caney's initial claim, that "if someone's parents had mated at a different time, then, of course, a different person would have been born". Similar claims are made throughout

\footnotetext{
${ }^{23}$ Edward Page, "Intergenerational justice and climate change", Political Studies 67 (1999), 53-66 at p. 58.

${ }^{24}$ Page, pp. 63-5. A similar group-based argument in relation to the general rectification of historic injustice is made by James Fishkin, "Justice between generations", in John W. Chapman (ed.), NOMOS XXXIII: Compensatory Justice (New York: New York University Press, 1991), 85-96.

${ }^{25}$ For example, Avner de-Shalit's account of transgenerational communities is certainly communitarian in nature, but is more concerned with the relation of current generations to those living in the future than with arguments than with claims that those in the present have environmental duties to others as a result of their community's historical actions. So he writes that, “....contrary to the conservative concept of community, which looks backwards and sees an obligation to continue the heritage of previous generations, I advance a concept of the transgenerational community that extends into the future" (Avner de Shalit, Why Posterity Matters: Environmental Policies and Future Generations (London: Routledge, 1995), pp. 14-5.) This is not to say that a backward-looking account of remedial obligations could not be constructed from de Shalit's premises.
} 
the literature, stretching back to Parfit's original account of the non-identity problem in Reasons and Persons. Now, in all probability, this is the case. But it is not unquestionably so. We can, in fact, imagine a possible universe where it is both the case that $X$ came into existence, through the same conjunction of ovum and sperm, and where the factory did not release poisonous fumes. Such an outcome may be wildly implausible, but that does not necessarily matter when we construct counterfactuals to assess questions of benefit and harm. Suppose the situation is slightly different, so that $X$ has recently been harmed by poisonous fumes from a factory which have just been released. Because of this harm, she is hospitalized and is unable to go on a school trip, which in all probability is what she would have done had she not inhaled the fumes.

Subsequently, all those on the trip die when a second factory releases even more harmful gases next to their hotel. It is now the case that there is a real sense in which the release of fumes has benefited her - were it not for first instance of pollution she would have been, in all probability, killed by the second. Nonetheless, in order to assess the compensation she is due from the factory owner, we construct a non-probabilistic counterfactual, where she both does not inhale the fumes and is not killed in the nuclear accident. My claim is that it is possible to do just this in the case of assessing whether or not a present day party has benefited from or has been harmed by historic processes of industrialization. Here, my argument reflects that of writers such as Woodward and Kavka, who have argued that it is possible for future generations to have their rights violated even though they are not harmed in an overall sense, if particular interests which they have are harmed. ${ }^{26}$ In order to assess the extent to which this right-violating harm to an interest should be compensated for, we construct a counterfactual where the right is not violated. ${ }^{27}$ Often this tries to predict what would most likely have happened had the right violation not taken place, but sometimes this is simply not appropriate, and this is particularly so in cases where a rights violation ends up having a net positive effect on the victim of the violation. Sometimes, these counterfactuals are extremely unlikely to have occurred in practice - but nonetheless they are the appropriate mechanism in order to assess the allocation of remedial duties. Had the historic emission of GHGs not occurred, it is indeed exceedingly improbable that the vast majority of the people in the world would exist in the present day. But in assessing whether or not the individuals who do exist have benefited or been harmed by these emissions, we can imagine a possible world both where the emissions did not take place, and where patterns of reproduction, however improbably, happened in such a way as to give rise to the exact same set of individuals who now exist. ${ }^{28}$ As such, the non-identity problem is not a problem. ${ }^{29}$

\section{3 - The Ongoing Responsibility for Failing to Fulfill Remedial Obligations}

\footnotetext{
${ }^{26}$ James Woodward, "The non-identity problem”, Ethics 96 (1986), 804-31; Kavka, "The paradox of future individuals". For discussion see Cecile Fabre, Justice In a Changing World (Cambridge: Polity, 2007), 4550.

${ }^{27}$ For further discussion of the use of counterfactuals, see Joel Feinberg, "Wrongful life and the counterfactual element in harming", in Freedom and Fulfillment: Philosophical Essays (Princeton: Chichester, 1992), 3-36

${ }^{28}$ Whether this is, in fact, the best counterfactual to use is an open question - it may be better to imagine a world where, for example, emissions did take place, but where non-emitting communities with full information were consulted and compensated for the future effects of these emissions. My point here is simply that the probabilistic counterfactual is not the right one to employ in this instance.

${ }^{29}$ I have only been able to give the briefest outline here of how counterfactual reasoning should operate in cases of harm and benefit from pollution. I give a fuller account of this issue in my forthcoming book, Rectifying International Injustice: Compensation and Restitution Between Nations (Oxford University Press).
} 
The argument of the preceding question maintains that the non-identity problem should not be interpreted in such a way as to rule out backward-looking accounts of remedial obligations out of hand. Thus, on my account, the "beneficiary pays" principle stands as a morally relevant form of connection with historic pollution. But what of the responsibility based argument for the polluter pays principle, which seeks to accord remedial obligations to the communities responsible for historic pollution? Does all its force in fact depend upon the contingent fact that the national communities which were originally responsible for pollution have typically benefited from the polluting acts in question? Henry Shue has put forward a strong defence of the principle that those responsible for pollution should bear the costs of dealing with its effects. ${ }^{30}$ In response to the objection that this involves placing costs upon individuals who were not responsible for the actions in question, he admits the force of the principle, "that one person ought not be held responsible for what is done by another person who is completely unrelated." But, he notes, "“[c]ompletely unrelated' is, however, a critical portion of the principle. To assume that the facts about the industrial North's contribution to global warming straightforwardly fall under this principle is to assume that they are considerably simpler than they actually are." 31 He writes:

Nothing is wrong with [this] principle... It is indeed not fair to hold someone responsible for what has been done by someone else. Yet that principle is largely irrelevant to the case at hand, because one generation of a rich industrial society is not unrelated to other generations past and future. All are participants in enduring economic structures. Benefits and costs, and rights and responsibilities, carry across generations. ${ }^{32}$

This account runs together the "beneficiary pays" principle with a different approach, which rather than focusing on the benefit one receives, looks at the sense in which the fact that one is a member of a given national community means that one inherits responsibilities from one's forebears. Various writers have found this idea appealing. Sometimes this is based on the idea that assuming some responsibility for the actions of one's ancestors is a necessary component of the idea of national identity. Thus Tony Honore argues explicitly for the assumption of responsibility for the unintended results of state action:

Our identity and integrity depend upon taking responsibility for the way in which we act or have acted in the past even in its unintended aspects. The same is true by analogy of states. To accept responsibility for the unintended consequences of state action or default (e.g. the deaths in the Irish famine of 1845, the Armenian deportations of 1915 onwards, the concentration camps of the Boer War), can be for a nation the condition of self-respect and of reconciliation with the unintended victims of government action. ${ }^{33}$

Clearly, if such an approach is taken, the problem of who should bear the costs associated with historical emissions seems straightforward - they represent (at best) the unintended consequences of one's community's earlier actions. Many liberal theorists reject this out of hand, as conflicting with axiological individualism. In what follows, I suggest a way in which responsibility for some acts of pollution can indeed be seen to be transmitted across generations, even on expressly individualistic principles. My model here is based upon other work on the way that responsibility for rectifying injustice can be passed on from one generation to another within national communities. As such, it rests upon a claim that at least some acts of pollution either themselves constitute, or give rise to, acts of injustice. This can arise in two ways. The first is when a polluting act is itself an act of injustice, involving some sense of wrongdoing or culpability. It is

\footnotetext{
${ }^{30}$ Henry Shue, "Global environment and international inequality", International Affairs 79 (1999), 531-45.

${ }^{31}$ Shue, p536.

${ }^{32}$ Shue, pp536-7.

${ }^{33}$ Tony Honoré, "Being responsible and being a victim of circumstance", in Responsibility and Fault (Oxford: Hart Publishing, 1999), 121-42 at p133. See also "Inheriting responsibilities" in David Miller's forthcoming book National Responsibility and Global Justice (Oxford University Press).
} 
key here that negligence, in terms of one not taking sufficient care in relation to one's actions, can be culpable in this sense. Many cases of environmental pollution as injustice will not be instances where one community deliberately causes direct environmental damage to another - although such events have taken place. Environmental damage has long been a part of military warfare: one may think of biblical accounts of sowing the seeds of one's enemy's fields with salt so as to prevent crops growing; of "scorched earth" policies, where advancing or withdrawing armies deliberately destroy anything in their path that might be of use to the enemy; or of the lasting environmental effects of modern warfare, in relation to depleted uranium shells, Agent Orange herbicides or even conventional nuclear weapons. In such cases, if we deem the military action in question to be unjust, the environmental damage is a straightforward example of deliberately wrongful international interaction. But also included are examples where a given community causes damage to the environment of another (either without, or in conjunction with, causing damage to their own environment) by either negligently not knowing what the effects of their actions would be, or by knowing but not caring sufficiently, and acting in damaging fashion regardless. The second way in which acts of pollution can give rise to injustice is when those responsible for causing harm to others fail to repair the damage caused by their actions. In this case, the original polluting act may have been performed perfectly innocently, without either malice or negligence. Nonetheless, if we maintain that such actions give rise to compensatory obligations, then a failure to fulfill these duties itself constitutes an act of injustice.

Let us set up a paradigm case of unjust international pollution, whereby a given nation commits a polluting act which clearly causes harm to members or property of another nation. Suppose that Nation A deliberately conducts a nuclear test in a remote part of its own territory, with obvious and predictable damage to neighbouring Nation B. Or perhaps Nation A negligently allows one of its military oil tankers to spill its load in the waters of Nation B, and refuses to assist in a clear-up. Or Nation A sites a power plant at the edge of its territory, upwind of Nation B, with the unforeseen consequence that deforestation occurs in Nation B as a result of acid rain. Nation A refuses to compensate Nation B for the effects of its actions. One hundred and fifty years later, the effects of Nation A's actions may still be felt in Nation B - but it seems as if Nation A can plausibly maintain that such effects are the results of the actions of a previous generation, and that the present inhabitants of Nation A cannot be held morally accountable for paying compensation. And if, as is quite possible, Nation A is no longer benefiting from these original actions, it is not immediately clear how an account based on, for example, morally objectionable free-riding can continue to maintain the "polluter pays" principle.

My argument as to how Nation A still can be held responsible in certain cases is based upon the idea that the ongoing failure of a collectivity over time to rectify its own unjust actions itself constitutes an act of injustice. I have laid out the model this rests upon in some detail elsewhere, and shall just summarise it here. ${ }^{34}$ The model rests upon three relatively uncontroversial propositions which concern:

i) the nature of rectificatory duties;

ii) nations and collective responsibility; and

iii) nations and overlapping generations

The claim of (i) is that the failure to rectify an injustice for which one is responsible itself constitutes an act of injustice. Take the previous example, of where A refuses to clear up an oil spill for which it is responsible. Let us imagine that B pays the bill for the spill instead. This is

\footnotetext{
${ }^{34}$ For the full account, see Daniel Butt, "Nations, overlapping generations and historic injustice", American Philosophical Quarterly 43 (2006), 357-67. For discussion, see Fabre pp. 146-7.
} 
evidently not the end of the matter - A must now refund the money which B spent. For so long as it does not do this, A is guilty of an ongoing act of injustice.

The claim of (ii) is the most controversial of the three (indeed, is probably the only one of the three which is controversial). This is the idea that it can be possible to hold nations collectively responsible for the actions of their political leaders. This needs some explanation. First, it maintains only that it is possible to hold a people collectively responsible for their leaders' actions. It is left as an open question what kind of relations between leader and people give rise to such an outcome. So whether we want to hold those living in non-democratic regimes responsible is open to debate, but many theorists are happy to ascribe such responsibility in the case of democracies at least. As David Miller writes, “...the more open and democratic a political community is, the more justified we are in holding its members responsible for the decisions they make and the policies they follow." ${ }^{35}$ Second, we need not take "responsibility" here to mean "moral responsibility". Different individuals in the polity, who voted for or supported the policy in question, may well be said to bear moral responsibility, but all that is necessary here is to maintain that the collective as a whole bears what Tony Honoré calls "outcome responsibility": a responsibility to bear the costs of dealing with the outcome. ${ }^{36}$ (It is still open to the collective, of course, to distribute the costs of doing so differentially internally so that the primary burden falls upon those who were morally responsible.) As Walzer argues, "Even in a perfect democracy, it cannot be said that every citizen is the author of every state policy, though every one of them can rightly be called to account." 37

Finally, (iii) points out that when we think of the existence of communities over time, a model of overlapping generations is more realistic than a model of successive generations. If we consider a national community, it is not the case that as one generation dies another takes its place. People are dying and being born all the time, but this fact does not mean that the nation as a whole is, in a meaningful sense, different when this happens. In the oil spill example, A cannot avoid its compensatory obligations the day after the spill by maintaining that, since the accident, its membership has changed, meaning that the entity which had responsibility yesterday no longer exists. Nations are what Peter French has called a "conglomerate collectivity":

A conglomerate collectivity is an organization of individuals such that its identity is not exhausted by the conjunction of the identities of the parties in the organization. The existence of a conglomerate is compatible with a varying membership. A change in the specific persons associated in a conglomerate does not entail a corresponding change in the identity of the conglomerate. ${ }^{38}$

If we take these three principles together, we can see how responsibility for failing to rectify injustice can persist across time, even after everyone who was responsible for the original action has died. Insofar as the failure to rectify an act of injustice is itself an act of injustice, a nation which continues to fail to correct its actions is guilty of ongoing collective wrongdoing. The nature of the act of injustice in question will change over time, so that later generations are not so much responsible for failing to rectify the original act of injustice as responsible for failing to rectify the later, ongoing failure to rectify the original act of injustice. But responsibility persists regardless. This is due to the gradual way in which the population of the nation changes over time. Say the original polluting act took place at time T. At T, Nation A owes Nation B

\footnotetext{
${ }^{35}$ Miller, "Holding nations responsible", Ethics 114 (2004), 240-68 at p. 262.

${ }^{36}$ Tony Honoré, 'Responsibility and luck', Law Quarterly Review 104 (1988), 530-53.

${ }^{37}$ Michael Walzer, Just and Unjust Wars, (New York: Basic Books, 1977), p. 299.

${ }^{38}$ Peter French, Collective and Corporate Responsibility (New York: Columbia University Press, 1984), p13.
} 
compensation for this polluting act. Suppose it refuses to pay this compensation. This constitutes an act of injustice against B. A year later, at T1, A is still refusing to pay compensation. The principle of collective responsibility holds that all members of $A$ are now implicated in this act of injustice - including those members of the collectivity who were not members at $\mathrm{T} 1$. Two years later, at T2, the membership of A will again have changed somewhat- but not to the extent that A does not owe A compensation for refusing to pay compensation at T1. And, again, if A fails to do so, then all members of $\mathrm{A}$ - including those who were not alive either at $\mathrm{T}$ or at $\mathrm{T} 1$ - bear collective responsibility for the act of injustice A commits at T2. In time, there will be no member of A who was alive at T. But all members of A will be collectively responsible for the ongoing failure to pay compensation to $\mathrm{B}$. The key distinction between the original act of injustice and the subsequent failure to rectify injustice is that the former is located at a particular temporal point, whereas the second is ongoing. Both constitute acts of injustice, but only the latter is of such a character as to implicate new members of the collectivity in injustice. This is why there is a sense in which secondary responsibility (to rectify injustice) can be inherited, whereas primary responsibility (for the act of injustice itself) cannot. Insofar as a self-governing community continues to fail to rectify the unjust effects of its polluting acts, it acts unjustly across time. This implicates new entrants into the political community in an ongoing environmental injustice.

\section{4 - Climate Change and Ignorance of Injustice}

I have suggested that there are two ways in which present day generations can bear particular, backward-looking duties to bear the costs of environmental damage: the first stemming from benefit; the second from responsibility. In relation to the responsibility argument, I have outlined a model whereby nations can be held collectively responsible for the unjust actions of their leaders. There is no doubt that there are many cases of environmental damage where such culpable action by governments is indeed a real issue. This can apply to cases where governments themselves caused pollution, either by their deliberate actions or by their negligence; to cases where governments failed to stop pollution, by setting quotas, prohibiting certain practices; and subsequently to cases where governments fail to rectify the effects or pay the costs of polluting acts for which they bear responsibility. It is important that the argument from responsibility is not simply set aside in favour of the benefit argument when it comes to allocating the costs of environmental damage; indeed, in many cases, the responsibility approach should be seen as prior, in that we should allocates costs to those responsible for wrongful pollution before allocating them to those who merely have benefited from said pollution, insofar as they are different. But undeniably there is a sense in which the responsibility model is particularly unsuited to consideration of historical greenhouse emissions. The problem here is that the extent to which historical emissions can be seen as examples of wrongful pollution is highly debatable, given the claim that our knowledge of the effects of these emissions is a relatively recent development. Such an account clearly needs to refer to some version of the precautionary principle - performing actions whose effects are unknown can obviously be negligent in certain situations. It is also the case that ignorance as to the effects of particular actions must be genuine and non-culpable: so Allen Buchanan, for example, writes in a different context of the possibility of "culturally induced factual ignorance" for which agents can be culpable - here even genuine ignorance is no defence. ${ }^{39}$

\footnotetext{
${ }^{39}$ Allen Buchanan, "Judging the past: the case of the human radiation experiments", in Ronald Munson (ed.), Intervention and Reflection: Basic Issues in Medical Ethics (Belmont, California: Wadsworth, 2000), 525-530 at p528.
} 
But let us be generous to those responsible for the first tranche of historical emissions, and accept that they were acting in perfectly innocent fashion. ${ }^{40}$ In relation to these actions, it does seem to be the case that, on the individualistic account, only benefit and not responsibility can come into play. This is quite right. If we find a category of historic actions which have turned out to have harmful consequences, but which a) did not involve any culpable wrongdoing, either in the original commission of the acts or in the subsequent failure to seek to rectify the acts and $b$ ) are not benefiting anyone in the present day, then it would quite wrong to hold the descendants of those who committed the actions responsible for these costs. On an individualistic account, that would be simply arbitrary and unfair. We have three primary responses available: to let the costs fall where they lie, on those who suffer the effects of the actions in question; to share the costs equally between all other parties; or to ask those most able to pay to do so. To a large extent, which option we choose will depend upon our background theory of distributive justice. These early emissions, however, were clearly produced in connection with actions which have benefited contemporary industrial economies to a great extent, and so the benefit model seems the most appropriate to employ in relation to these historical emissions. But this certainly does not mean that we should simply assess contributions to the costs of climate change in the present day based on the benefit model alone. For, as Shue argues:

...the industrial states' contributions to global warming have continued unabated long since it became impossible to plead ignorance. It would have been conceivable that as soon as evidence began to accumulate that industrial activity was having a dangerous environmental effect, the industrial states would have adopted a conservative or even cautious policy of cutting back greenhouse emissions or at least slowing their rate of increase. For the most part, this has not happened. ${ }^{41}$

There are different candidates for the date when knowledge concerning emissions was such so as to require such a reaction - Gosseries lists 1840,1896, 1967, 1990 and 1995 as possibilities. But once this point was reached, the behaviour of the great majority of the industrial states was no longer innocent. They became guilty of injustice - both in their ongoing environmental policies, and in their failure to pay the costs associated with their wrongful actions to date. So insofar as many developed states are still failing to fulfill their responsibilities, their members are collectively responsible for serious wrongdoing. Quite how much work, in the present world, is done by the benefit model and how much by the responsibility model is an open question. But what is clear is that as time goes on, if, as seems likely, many industrial nations refuse to act in the way that justice requires, then the responsibility model will become more and more significant.

\section{Conclusion}

There is a commendable generosity of spirit to be found in forward-looking accounts of the allocation of remedial duties in response to historic pollution. In focusing on the capacity of modern day states to right the lasting effects of historic wrongs, they demonstrate a willingness to let bygones be bygones, and rest their arguments on why the developed world should lead the way in addressing the costs of climate change on progressive principles of fairness and equality. It is not surprising, this being the case, that such theorists are often cosmopolitans when it comes to international distributive justice - Caney and Moellendorf being obvious examples. But there is

\footnotetext{
${ }^{40}$ Andrew Williams has suggested to me that, on the basis of what we know of our ancestors, it is hard to believe that they would have acted differently even had they known what the effects of their actions would be! Such an observation, which seems highly plausible, seems to undercut the basis of approaches such as that of Samuel C. Wheeler III, who bases his (very limited) account of current day rectificatory duties on generous assumptions concerning the moral character of his ancestors.

${ }^{41}$ Shue, p536.
} 
also a danger in too tight a focus on the forward-looking capacity argument. The worry is that those in developed states who are not cosmopolitans, and who thus assign ethical significance to state boundaries and resist the claims of redistributive egalitarianism in an international context, will fail to see why the developed world should meet these costs - its greater capacity to do so notwithstanding. If we cannot say either that the developed world is responsible for injustice in the present day in relation to its dealings with other states or that it has benefited, and others have suffered, as a result of historic pollution, why should it meet these costs? The danger is thus that for those who are not cosmopolitans, a rejection of backward-looking principles of rectificatory justice in connection with historic pollution all too easily leads to the conclusion that the costs of historic GHG emissions should be left to lie where they fall. My suggestion is that the limited defence of backward-looking principles given in this paper is likely to be of use in real world policy debates, where the majority of political actors are not, in fact, egalitarian cosmopolitans. The principle of common but differentiated responsibility used in real world policy discussions makes explicit reference to the history of the development of the industrialized states, both in terms of benefit and of responsibility. In a world of extremely limited redistribution across state boundaries, the history of resource holdings and of the character of international interaction matters. This is why backward-looking principles are important, and should not be disregarded lightly. $^{42}$

\footnotetext{
${ }^{42}$ I would like to thank participants in the Applied Global Justice Network Conference on Environmental Justice, Sustainable Development and Future Generations, held in Louvain-La-Neuve in February 2006, and Axel Gosseries in particular, for their comments on this paper.
} 